\title{
All-Trans Retinoic Acid Enhances Matrix Metalloproteinase 2 Expression and Secretion in Human Myeloid Leukemia THP-1 Cells
}

\author{
Hien Thi Vu, Thi Xoan Hoang $(\mathbb{D}$, and Jae Young Kim \\ Department of Life Science, Gachon University, Seongnam, Kyeonggi-Do 461-701, Republic of Korea \\ Correspondence should be addressed to Jae Young Kim; jykim85@gachon.ac.kr
}

Received 22 May 2018; Accepted 13 August 2018; Published 26 August 2018

Academic Editor: Marija Mostarica-Stojković

Copyright (c) 2018 Hien Thi Vu et al. This is an open access article distributed under the Creative Commons Attribution License, which permits unrestricted use, distribution, and reproduction in any medium, provided the original work is properly cited.

\begin{abstract}
All-trans retinoic acid (ATRA) is an effective drug for the induction therapy of acute promyelocytic leukemia. However, the treatment is associated with adverse events such as retinoic acid syndrome (RAS) in some patients, whose histologic characteristics included organ infiltration by leukemic cells. Matrix metalloproteinase 2 (MMP-2) is often upregulated in tumor cells and plays a role in tumor cell migration and invasion by degrading the extracellular matrix. In this study, we examined the possible modulatory effects of ATRA on MMP-2 expression and secretion in human myeloid leukemia cell line THP-1. The cells were treated with various concentrations of ATRA, and MMP-2 expression and secretion were examined. MMP-2 expression and secretion started to increase with ATRA concentration as low as $0.1 \mathrm{nM}$ and gradually increased thereafter. Agonists of retinoic acid receptor (RAR) or retinoid X receptor (RXR) alone could enhance MMP-2 secretion, and RAR or RXR antagonists alone could reverse ATRA-induced MMP-2 secretion. ATRA increased intracellular calcium ion levels, and a calcium-channel blocker inhibited ATRAinduced MMP-2 secretion. Dexamethasone suppressed ATRA-induced MMP-2 secretion. Our results suggest that ATRA enhances MMP-2 expression and secretion in human myeloid leukemia THP-1 cells in a calcium ion dependent manner through RAR/RXR signaling pathways, and this enhanced expression and secretion may be associated with the possible mechanisms of RAS.
\end{abstract}

\section{Introduction}

All-trans retinoic acid (ATRA) is the most abundant physiologically active metabolite of vitamin A. It plays important roles in a wide range of biological processes such as the immune response and cell growth, differentiation, and apoptosis $[1,2]$. ATRA has been used as an effective drug in the induction treatment of acute promyelocytic leukemia (APL) $[3,4]$. APL is characterized by a reciprocal balanced translocation between chromosomes 15 and 17 [5]. This translocation leads to the fusion of the retinoic acid receptor- $\alpha$ (RAR $\alpha)$ gene and promyelocytic leukemia (PML) gene, resulting in the formation of the PML/RAR- $\alpha$ fusion protein, which is involved in leukemogenesis [6,7]. The therapeutic effect of ATRA is characterized by the degradation of the PML/RAR $\alpha$ oncoprotein and differentiation of the malignant cells into phenotypically mature myeloid cells [8]. In addition to its therapeutic usefulness in APL, ATRA has recently attracted great attention for the treatment of other cancers because of its antiproliferative and proapoptotic properties [9].

Matrix metalloproteinases (MMPs) are a family of zinc-dependent endopeptidase, which may be secreted, membrane-bound, or intracellularly located [10]. They are involved in the physiological and pathological remodeling of the extracellular matrix (ECM) by cleaving ECM proteins such as collagen, fibronectin, elastin, and laminin [11]. In addition to their involvement in the normal tissue remodeling, MMPs also act on other substrates to regulate many cellular processes such as cell proliferation, adhesion, migration, apoptosis, chemotaxis, and signaling [11-14]. MMPs are often upregulated in tumor cells and play roles in tumor cell migration and invasion by degrading the ECM [15-18]. Among the 23 MMPs identified in humans [19], MMP-2 is widely expressed in tissues and cells [20]. Recently, the levels of MMP-2 secretion were directly used to evaluate the migration of various types of cells $[21,22]$. 
Previous in vitro studies showed that ATRA inhibited MMP-2 expression in human cancer cell lines from glioblastoma [23, 24], breast cancer [25], lung cancer [26], ovarian cancer [27], chondrosarcoma [28], and osteosarcoma [29], but it did not affect [30] or enhance [31] MMP-2 expression in neuroblastoma cell line. However, the role of ATRA in the regulation of MMP-2 expression in myeloid leukemic cells has not been clarified. The purpose of this study was to investigate the possible modulatory effects of ATRA on MMP-2 expression and secretion in human myeloid leukemia THP-1 cells.

\section{Materials and Methods}

2.1. Reagents and Chemicals. ATRA, RAR $\alpha$ agonist $\mathrm{BMS753}, \mathrm{RAR} \alpha$ antagonist $\mathrm{BMS195614}$, retinoid X receptor (RXR) $\alpha$ agonist LG100268, and pan RXR antagonist UVI3003 were purchased from Sigma-Aldrich (St. Louis, MO, USA). Antibiotic-antimycotic, HEPES (4-(2-hydroxyethyl)-1-piperazine ethane sulfonic acid) buffer, and $\beta$ mercaptoethanol were purchased from Invitrogen Corp (Gibco BRL, MD, USA).

2.2. Cell Culture and Treatment. THP-1 cells (Korean Cell Line Bank, Seoul, Korea) were maintained in RPMI 1640 culture medium (Welgene Inc., Daegu, Korea) with 10 mM HEPES buffer and $\beta$-mercaptoethanol supplemented with $10 \%$ heat-inactivated fetal bovine serum (FBS) and $1 \%$ antibiotic-antimycotic at $37^{\circ} \mathrm{C}$ in a $5 \% \mathrm{CO}_{2}$ humidified incubator. To measure the expression and secretion of MMP2 , the cells were cultured without FBS since it is known to contain large numbers of proteins, including MMP-2 and MMP-9 [32].

2.3. Western Blot Analysis. To measure the secreted MMP2 proteins, the culture supernatants were collected by centrifugation at $400 \times \mathrm{g}$ for $5 \mathrm{~min}$, and then concentrated using an Amicon Ultra-15 Centrifugal Filter Unit, $10 \mathrm{kDa}$ cut-off (Millipore Corp., Billerica, MA, USA) at $2000 \times \mathrm{g}$ for $20 \mathrm{~min}$. The supernatants were collected and the protein concentrations were measured with the Qubit fluorometer (Invitrogen Corp). Five micrograms of protein was subjected to $10 \%$ sodium dodecyl sulfate-polyacrylamide gel electrophoresis and blotted onto a polyvinylidene difluoride (PVDF) membrane (Millipore Corp.). The membrane was blocked with 5\% BSA in 1X TBST (2.68 mM KCl, 137 $\mathrm{mM} \mathrm{NaCl}, 25 \mathrm{mM}$ Tris- $\mathrm{HCl}$, and $0.05 \%$ Tween 20). Next, the membrane was probed with an anti-MMP-2 (42-5D11, Millipore Corp.) or an anti- $\beta$ actin antibody (Santa Cruz Biotechnology Inc., Dallas, TX, USA). The proteins of interest were detected with an HRP-conjugated goat anti-mouse IgG antibody (sc-2055; Santa Cruz Biotechnology Inc.) or donkey anti-goat IgG antibody (sc-2020; Santa Cruz Biotechnology Inc.) and visualized with ECL-West-Q Pico ECL Solution from GenDEPOT (Barker, TX, USA) using the ChemiDoc MP System (Bio-Rad, Hercules, CA, USA).

2.4. Gelatin Zymography. The THP-1 cells were cultured in a serum-free medium for $48 \mathrm{~h}$ with or without $1 \mu \mathrm{M}$ ATRA. The obtained conditioned media were mixed with nonreducing sample buffer and incubated at room temperature for $10 \mathrm{~min}$. The samples were then loaded onto a $10 \%$ acrylamide gel containing $0.1 \%$ gelatin type A. After electrophoresis, the gel was washed with $2.5 \%$ Triton X-100, followed by incubation with developing buffer overnight at $37^{\circ} \mathrm{C}$. The gel was then stained with Coomassie brilliant blue and destained with a methanol-acetic acid solution. The gel was visualized on a light box.

2.5. Flow Cytometry. To determine the cell surface expression of MMP-2, the cells were first incubated with a purified anti-MMP2 antibody (42-5D11, EMD Millipore Corporation) for $30 \mathrm{~min}$ and then with the phycoerythrin-conjugated secondary antibody (Mouse IgG, CLCC35004, Cedarlane Lab, Burlington, Ontario, Canada) at $4^{\circ} \mathrm{C}$ for $30 \mathrm{~min}$. After washing twice with phosphate buffered saline (PBS), the cells were resuspended in PBS and analyzed on a Cytomics FC500 MLP (Beckman Coulter Inc., Fullerton, CA, USA).

2.6. Quantitative Real-Time Polymerase Chain Reaction ( $q R T$ $P C R)$. To analyze the MMP-2 expression, total RNA was extracted with the Qiagen RNeasy kit (Qiagen, Hilden, Germany) according to the manufacturer's instructions. The RNA concentrations were determined with an SD2000 microspectrophotometer (Bioprince, Atlanta, GA, USA). cDNA was synthesized from $2 \mu \mathrm{g}$ of total RNA with an MMLV reverse transcriptase (Bioprince) using an oligo dT primer (Bioprince) at $65^{\circ} \mathrm{C}$ for $1 \mathrm{~h}$. qRT-PCR was performed on the iQ5 multicolor Real-Time PCR detection system using an iQ SYBR Green Supermix (Bio-Rad). PCR amplification was performed using the following primer sets: MMP- $25^{\prime}$ ttgacggtaaggacggactc- $3^{\prime}, 5^{\prime}$-acttgcagtactccccatcg- $3^{\prime}, \beta$-actin $5^{\prime}$-gggacctgactgactacctc- $3^{\prime}$, and $5^{\prime}$-agcttctccttaatgtcacgc $-3^{\prime}$. The sample was normalized using the human $\beta$-actin gene as an endogenous control. For each sample, the relative abundance of the target mRNA was calculated from the $\mathrm{C}^{\Delta \mathrm{t}}$ values for both the target and endogenous reference gene using the $2^{-\Delta \mathrm{Ct}}$ cycle threshold method.

2.7. Enzyme-Linked Immunosorbent Assay (ELISA). The secreted MMP-2 was quantified using the Human MMP-2 ELISA Kit (ab100610, Abcam, Cambridge, UK) according to the manufacturer's instruction, and the absorbance was measured with an ELISA Reader ( $\mu$-Quant, Bio-Tek Instruments, Winooski, USA) at $450 \mathrm{~nm}$.

2.8. Intracellular Calcium Measurement. After removing the growth medium, the cells were washed with calcium-free HBSS (Invitrogen) and $20 \mathrm{mM}$ HEPES assay buffer ( $\mathrm{pH} 7.2$, Invitrogen). The cells were then mixed with $100 \mu \mathrm{l}$ of Fluo-4NW-dye, obtained from Molecular Probes (Invitrogen), and incubated for $30 \mathrm{~min}$ at $37^{\circ} \mathrm{C}$. Following an additional 30 min incubation at room temperature in the dark, the fluorescence signals were measured using the Cytomics FC500 MLP (Beckman Coulter Inc.) with appropriate for excitation and emission settings of $494 \mathrm{~nm}$ and $516 \mathrm{~nm}$, respectively. 


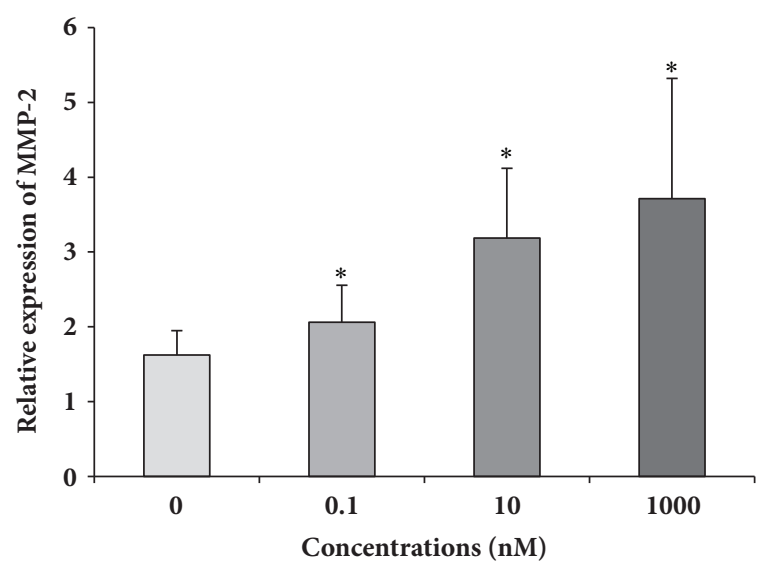

(a)

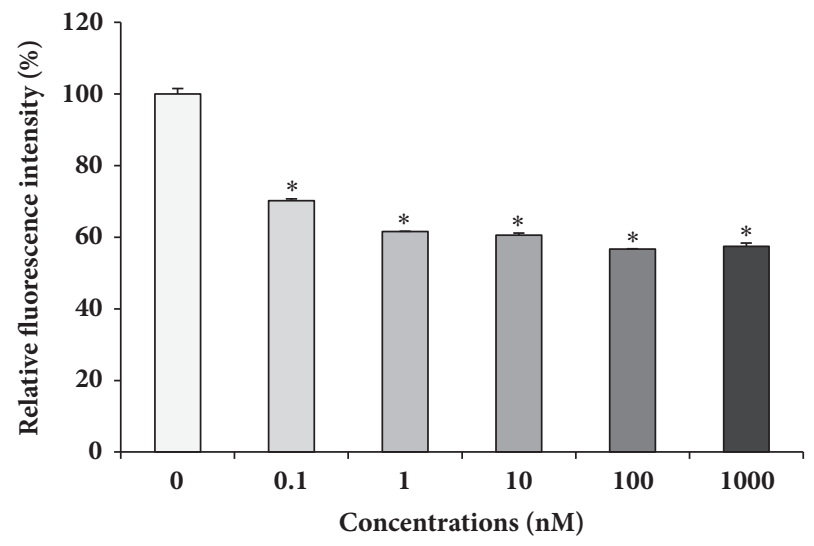

(c)

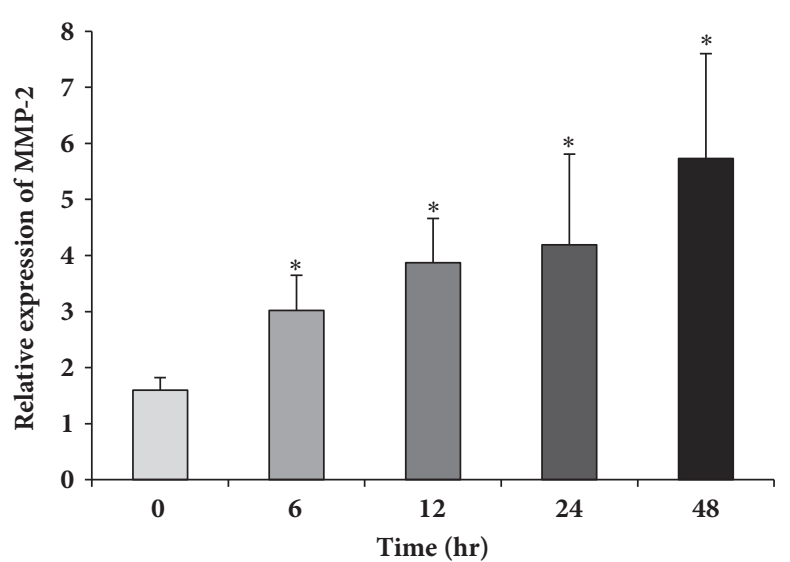

(b)

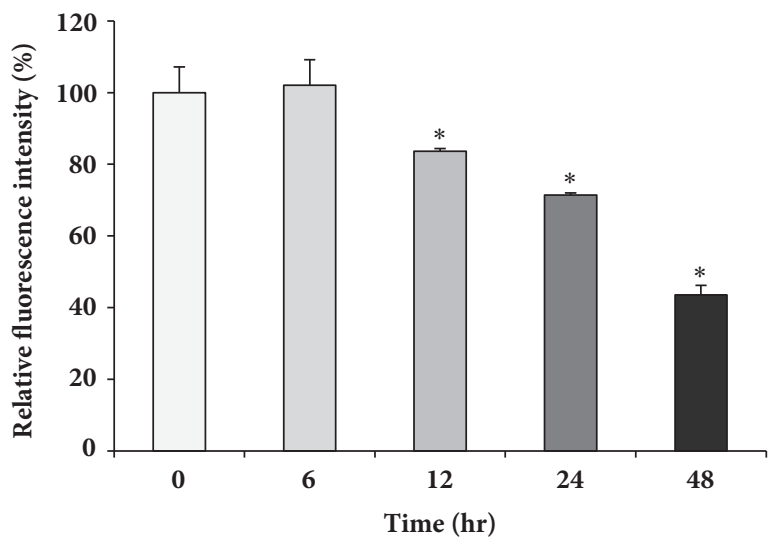

(d)

FIGURE 1: ATRA upregulates MMP-2 mRNA expression but suppresses its cell surface expression of THP-1. THP-1 cells were treated with the different concentrations of ATRA as indicated above for $24 \mathrm{~h}$ (a and c) or with $1 \mu \mathrm{M}$ (b) or $100 \mathrm{nM}$ (d) ATRA for various time points as indicated above. The expression of MMP- 2 mRNA was determined by qRT-PCR and was normalized to that of $\beta$-actin (a and b). The cell surface expression of MMP-2 was analyzed by flow cytometry (c and d). Bar graphs show the relative gene expression \pm SD. $*$ P $<0.05$ versus DMSO-treated control.

2.9. Statistical Analysis. All data were presented as mean \pm standard deviation $(\mathrm{SD})$, from at least three different experiments. The group means were compared using oneway analysis of variance (ANOVA), followed by post hoc test. All tests were performed using the SPSS statistical software version as mean \pm SD. $* \mathrm{p}<0.05$ was considered statistically significant.

\section{Results}

3.1. ATRA Enhances MMP-2 mRNA Expression, but Reduces Cell Surface MMP2 Expression. We examined the effects of ATRA on MMP-2 expression in the human myeloid leukemic cell line THP-1. The cells were treated with different concentrations of ATRA, ranging from 0.1 to $1000 \mathrm{nM}$ for $24 \mathrm{~h}$, and the MMP-2 mRNA expression was determined by qRT-PCR. MMP-2 mRNA expression started to increase at ATRA concentration as low as $0.1 \mathrm{nM}$ and peaked (3.7fold increase) in the presence of $1 \mu \mathrm{M}$ ATRA (Figure 1(a)). Thereafter, MMP-2 mRNA expression increased gradually, reaching approximately 5 times the control level at $48 \mathrm{~h}$ after treatment with $100 \mathrm{nM}$ ATRA (Figure 1(b)). Since it is known that MMP-2 can be membrane-bound or secreted [33], we first examined the cell surface MMP-2 expression using flow cytometry. As shown in Figure 1(c), cell surface MMP-2 expression started to decrease at an ATRA concentration of $0.1 \mathrm{nM}$, decreasing gradually thereafter, and reaching $60 \%$ of control levels after $1 \mu \mathrm{M}$ ATRA treatment (Figure 1(c)). Cell surface MMP-2 levels started to decrease $12 \mathrm{~h}$ after treatment with $100 \mathrm{nM}$ ATRA, decreasing significantly thereafter, and reaching around $50 \%$ of the control level at $48 \mathrm{~h}$ after the treatment (Figure 1(d)).

3.2. ATRA Induces MMP-2 Secretion in Dose- and TimeDependent Manners. To find the reason behind the reduction of the surface levels of MMP-2 by ATRA, despite MMP-2 mRNA upregulation, we measured MMP-2 secretion with both western blot and ELISA. The cells were treated with various concentrations of ATRA, ranging from 0.1 to 100 $\mathrm{nM}$ for $24 \mathrm{~h}$ and the culture supernatants were collected, concentrated by filtration, and subjected to western blot analysis. Secreted MMP-2 levels were markedly increased 


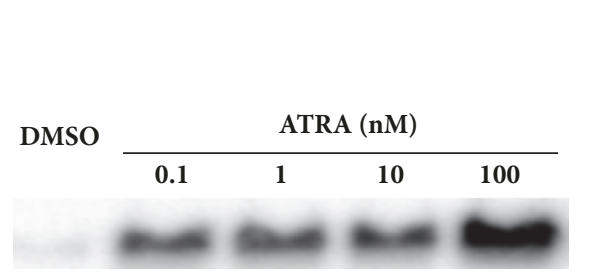

(a)

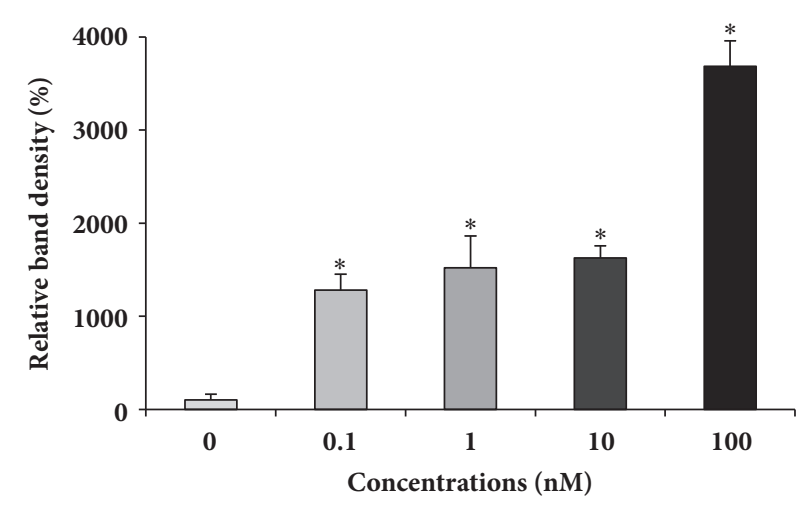

(d)

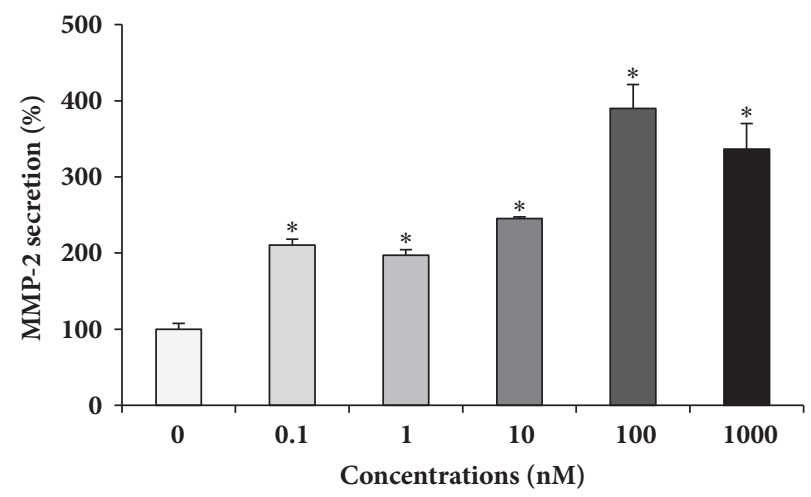

(f)

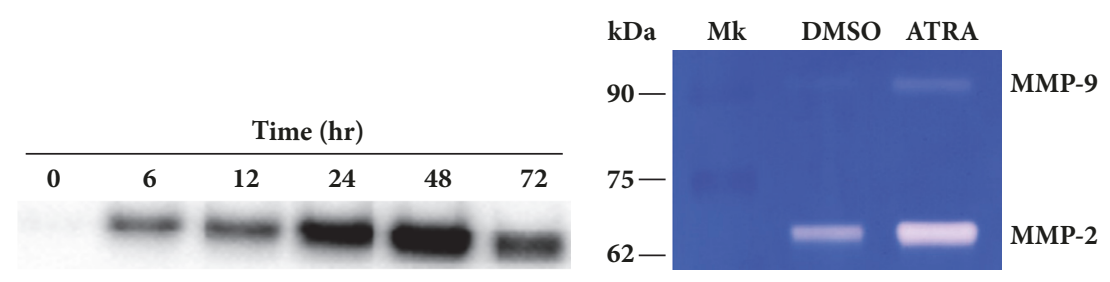

(b)

(c)

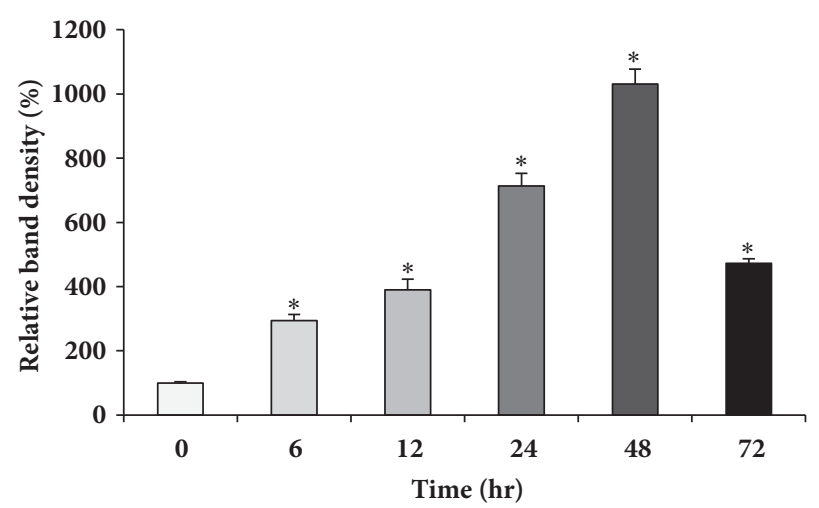

(e)

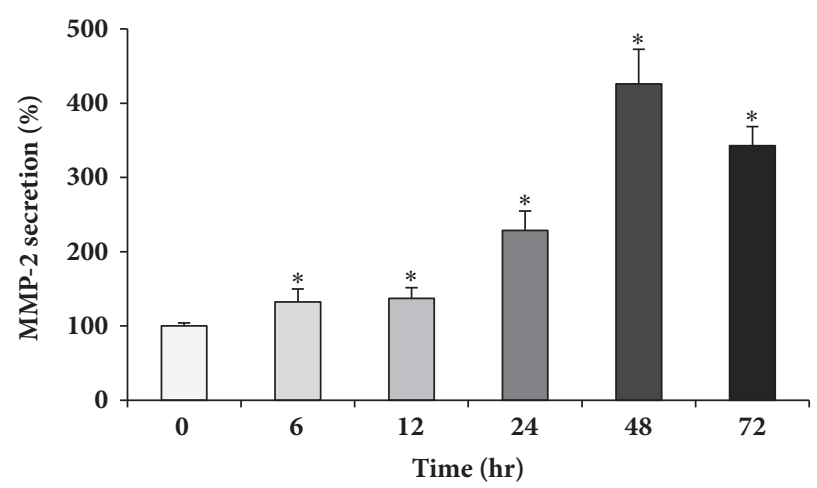

(g)

FIGURE 2: ATRA induces MMP-2 secretion in time- and dose-dependent manners. THP-1 cells were treated with different concentrations of ATRA indicated above ( $\mathrm{a}, \mathrm{d}$, and $\mathrm{f}$ ) or with $1 \mu \mathrm{M}$ ATRA for different time periods indicated above (b, e, and g). The culture supernatants were collected, concentrated by filtration, and subjected to western blot analysis ( $\mathrm{a}$ and $\mathrm{b}$ ). The culture supernatants were subjected to ELISA (f and g). Densitometry analysis of MMP-2 bands shown in ( $a$ and b) was performed by ChemiDoc MP System ( $d$ and e). A representative gel zymogram shows enhanced MMP-2 activity in ATRA-treated cells (c). $* \mathrm{P}<0.01$ versus DMSO-treated control.

by $0.1 \mathrm{nM}$ ATRA treatment, with a maximum increase of $3700 \%$ at $100 \mathrm{nM}$ ATRA concentration (Figures 2(a) and 2(d)). After treatment with $1 \mu \mathrm{M}$ ATRA, secreted MMP-2 levels gradually increased over time, reaching approximately $1000 \%$ of the control level at $48 \mathrm{~h}$, and decreased thereafter (Figures 2(b) and 2(e)). The increase in MMP-2 secretion, measured by western blot, was confirmed by ELISA which revealed similar patterns of increase in ATRA-inducedMMP-2 secretion (Figures 2(f) and 2(g)). To confirm that the secreted MMP-2 was the active form, we performed gelatinase zymography, which is commonly utilized to detect the gelatinolytic enzymatic activities of the active forms of both MMP-2 and MMP-9. As shown in Figure 2(c), the protein band of the MMP-2 active form (molecular weight $68 \mathrm{kD}$ ) in the ATRA-treated cells was thicker than that in the
DMSO-treated control cells, indicating that ATRA treatment induces the secretion of the active form of MMP-2.

3.3. ATRA-Induced MMP-2 Secretion Depends on the RAR/ RXR Pathway. Since both RAR and RXR play critical roles in ATRA-regulated gene expression [34], we examined whether MMP-2 secretion is affected by RAR/RXR agonists or antagonists. The cells were treated with different concentrations of RAR/RXR agonist, ranging from 0.01 to $1 \mu \mathrm{M}$ for $48 \mathrm{~h}$ in the absence of ATRA. The RAR agonist induced MMP2 secretion in a concentration-dependent manner, whereas the effect of RXR agonist on MMP-2 secretion was only pronounced at a concentration of $1 \mu \mathrm{M}$ (Figures 3(a)-3(c)). The levels of MMP-2 secretion, induced by treatment with 1 $\mu \mathrm{M}$ RAR agonist or RXR agonist, were comparable to those 


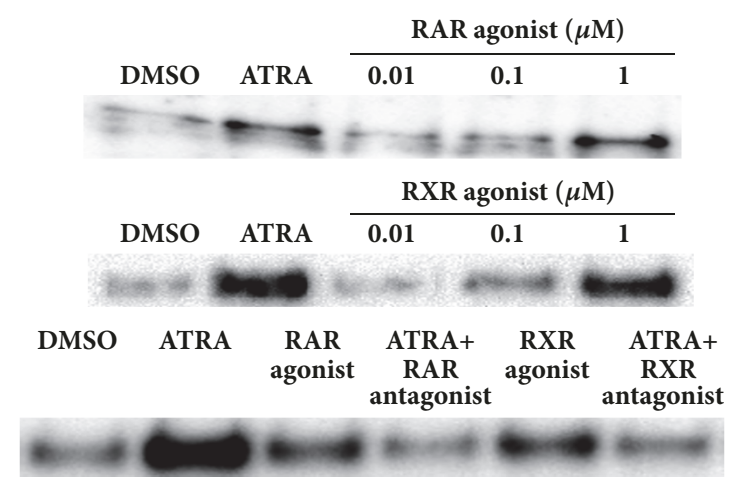

(a)

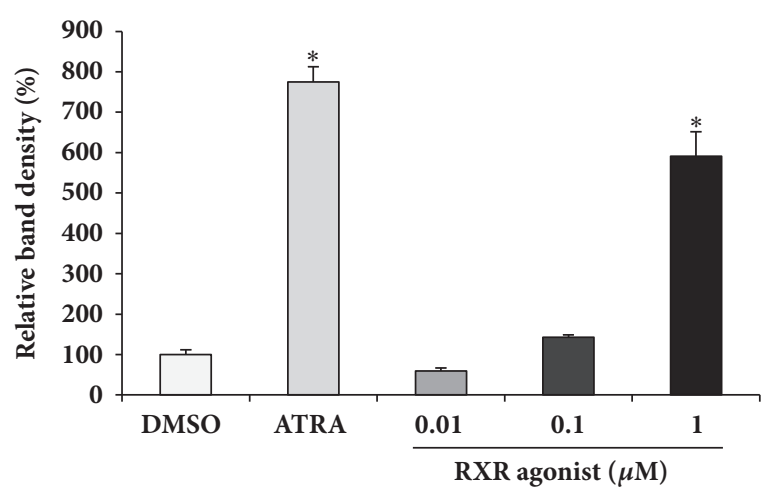

(c)

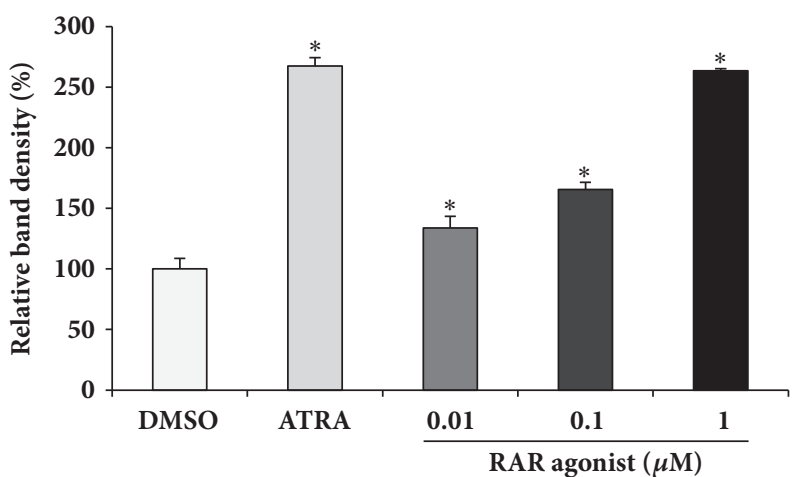

(b)

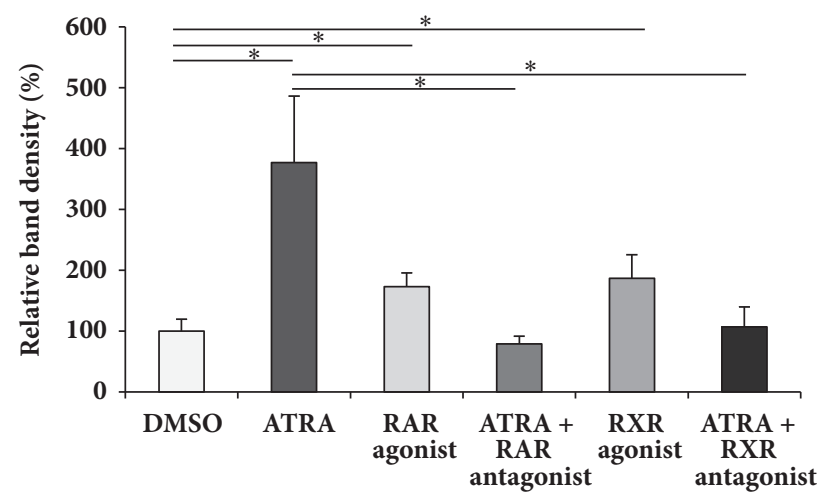

(d)

FIGURE 3: Effect of RAR/RXR agonists or antagonists on MMP2 secretion. Cells were treated with the different concentrations of RAR/RXR agonists indicated above (a, b, and c). Cells were treated with $1 \mu \mathrm{M}$ RAR/RXR antagonist in the presence of $100 \mathrm{nM}$ ATRA or with $1 \mu \mathrm{M}$ RAR/RXR agonist without ATRA for $48 \mathrm{~h}$ (a and d). The culture supernatants were collected, concentrated by filtration, and subjected to western blot analysis. Protein from each group was loaded at least three times on the gels. Densitometry analysis of MMP-2 bands shown in (a) was performed by ChemiDoc MP System (b, c, and d). $* \mathrm{P}<0.01$.

induced by $100 \mathrm{nM}$ ATRA treatment. To assess the effects of RAR/RXR antagonists on ATRA-induced MMP-2 secretion, the cells were treated with $1 \mu \mathrm{M}$ RAR or RXR antagonist in the presence of $100 \mathrm{nM}$ ATRA for $48 \mathrm{~h}$. As shown in Figures 3(a) and 3(d), the RAR or RXR antagonist completely reversed ATRA-induced MMP-2 secretion.

\subsection{ATRA-Induced MMP-2 Secretion Depends on Calcium} Ions. Since several studies have suggested the possible relationship between cellular calcium levels and enhanced MMP expression [35-37], we examined the intracellular calcium levels of ATRA-treated cells and performed experiments with calcium-channel blocker to evaluate the possible involvement of calcium ions in ATRA-induced MMP-2 secretion. As shown in Figure 4(a), treatment with ATRA led to a marked increase in the intracellular calcium levels in a timedependent manner. Verapamil, a calcium-channel blocker, significantly inhibited ATRA-induced MMP-2 secretion (Figures 4(b) and 4(c)), indicating the involvement of calcium ions in ATRA-induced MMP-2 secretion.

3.5. Dexamethasone Inhibits ATRA-Induced MMP-2 Secretion. Since it has been reported that the anti-inflammatory agent dexamethasone inhibits MMP-2 expression [27, 29] and cancer cell migration [38-40], we examined the effect of dexamethasone on ATRA-induced MMP-2 secretion in THP-1 cells. The cells were pretreated with dexamethasone at different concentrations for $2 \mathrm{~h}$, followed by ATRA treatment for $48 \mathrm{~h}$. The culture supernatants were concentrated and subjected to western blot analysis. As shown in Figure 5, $1 \mu \mathrm{M}$ or $10 \mu \mathrm{M}$ dexamethasone reversed ATRA-induced MMP-2 secretion, whereas $100 \mathrm{nM}$ dexamethasone had no effect on it (Figures 5(a) and 5(b)). The significant suppression of ATRAinduced MMP-2 secretion, achieved by treating THP-1 cells with $1 \mu \mathrm{M}$ or $10 \mu \mathrm{M}$ dexamethasone, was also confirmed by ELISA (Figure 5(c)).

\section{Discussion}

ATRA is known to suppress various types of cancers [41]. The mechanisms of the anticancer effects of ATRA include antiproliferation, proapoptosis, and metastasis inhibition [42]. For tumor invasion and migration, the tumor cells must modulate matrix degradation, cell-cell adhesion, and cell-matrix attachment [43]. MMPs mediate the invasive properties of tumor cells and promote angiogenesis through their ability to degrade basement membranes and remodel the ECM architecture [44-46]. In particular, MMP-2 plays 


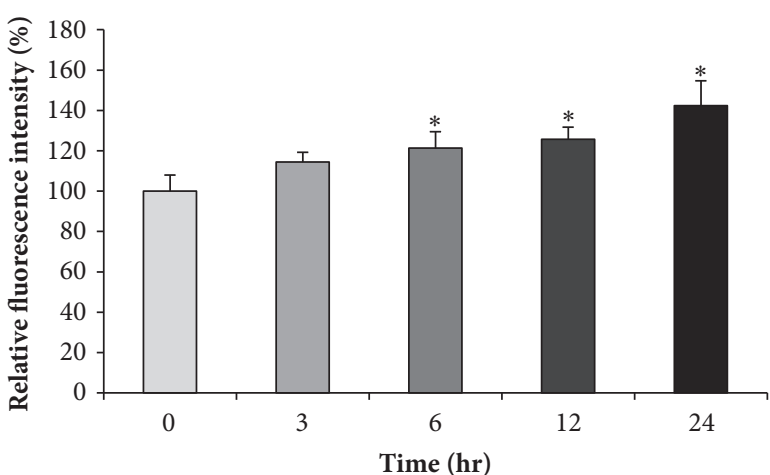

(a)

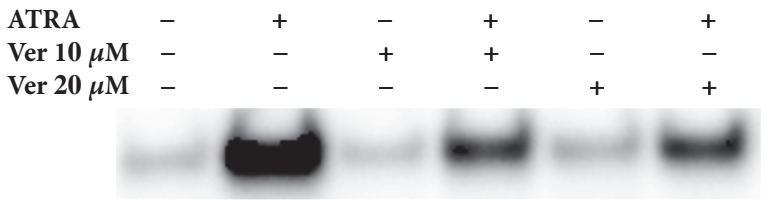

(b)

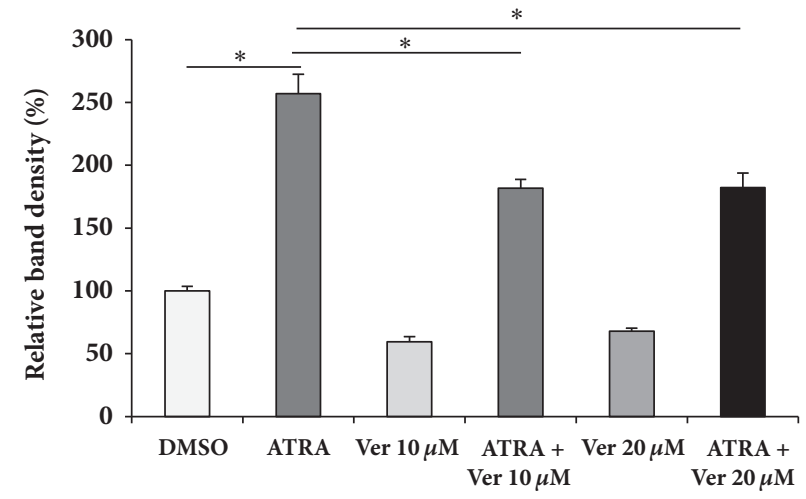

(c)

FIGURE 4: ATRA enhances MMP-2 secretion in a calcium-dependent mechanism. Cells were treated with 100 nM ATRA for various time periods indicated above. Then, cells were collected and intracellular calcium levels were measured by flow cytometry (a). Cells were treated with different concentrations of verapamil $(10$ or $20 \mu \mathrm{M})$ in the presence or absence of $100 \mathrm{nM}$ ATRA for $48 \mathrm{~h}$ (b and c). The culture supernatants were collected, concentrated by filtration, and subjected to western blot analysis (b). Densitometry analysis of MMP-2 bands shown in (b) was performed by ChemiDoc MP System (c). $* \mathrm{P}<0.05$.

a critical role in tumor cell invasion and metastasis [17, 45-47]. Most previous studies demonstrated that ATRA exerts inhibitory effects on the MMP-2 expression of various tumor types [23-29]. However, our results revealed that ATRA enhances both MMP-2 expression and secretion in human myeloid leukemia THP-1 cells. The reason for the discrepancy between the previous results and our current findings is unknown; however, it may be attributed to the different tumor types used in the studies. Unlike our study, where leukemic cells with indigenous migratory and invasive properties were used, all the previous studies cited above used tumor cells derived from nonleukocytic cells.

Although ATRA is generally well tolerated, development of retinoic acid syndrome (RAS) in some patients has been recognized as a distinct potential life-threatening complication, which is characterized by fever, dyspnea, hypotension, and weight gain [48]. The histologic characteristics of RAS include organ infiltration by leukemic cells [49]. ATRAinduced leukemic cell extravasation was found to be due to the increased adhesion and motility of these cells compared with their undifferentiated counterparts [50-52]. Although the underlying molecular mechanisms for the emigration of ATRA-treated leukemic cells into tissues are yet to be elucidated, this syndrome was effectively treated by administering dexamethasone and by withholding ATRA in severe cases [53-55]. In our study, MMP-2 expression and secretion in THP-1 cells were markedly enhanced by ATRA treatment and pretreatment of THP-1 cells with dexamethasone significantly inhibited ATRA-induced secretion of MMP-2. Since it is known that dexamethasone upregulates glucocorticoid receptor to inhibit NF- $\kappa \mathrm{B}$ activity [56], and that ATRA can induce NF- $\kappa \mathrm{B}$ activation [57], which results in MMP-2 expression and activation [58], we speculate that inhibitory action of dexamethasone may be due to a suppressive effect on NF- $\kappa \mathrm{B}$ activation. Based on our results, we suggest that ATRA-enhanced MMP-2 expression and secretion may be one of the major causes of RAS. However, to verify our hypothesis, further in vitro studies with matrigel invasion and transendothelial invasion assays using ATRA, RAR/RXR agonists or antagonists, and MMP-2 selective inhibitors, as well as animal studies, are necessary.

ATRA exerts various biological effects including regulation of gene expression by binding to the nuclear RARs $[59,60]$. ATRA binds to RAR to form heterodimers with $\mathrm{RXR}$. The RAR-RXR protein complex binds to retinoic acid response elements (RAREs) or retinoid X response elements (RXREs), each of which has a well-defined DNA sequence and induces gene transcription [61]. Our results revealed 


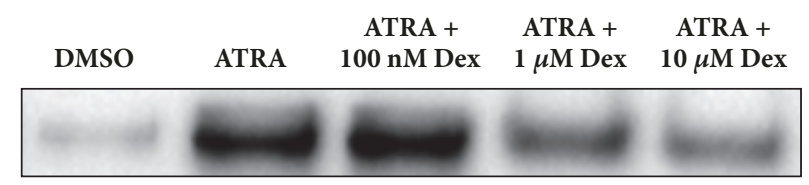

(a)

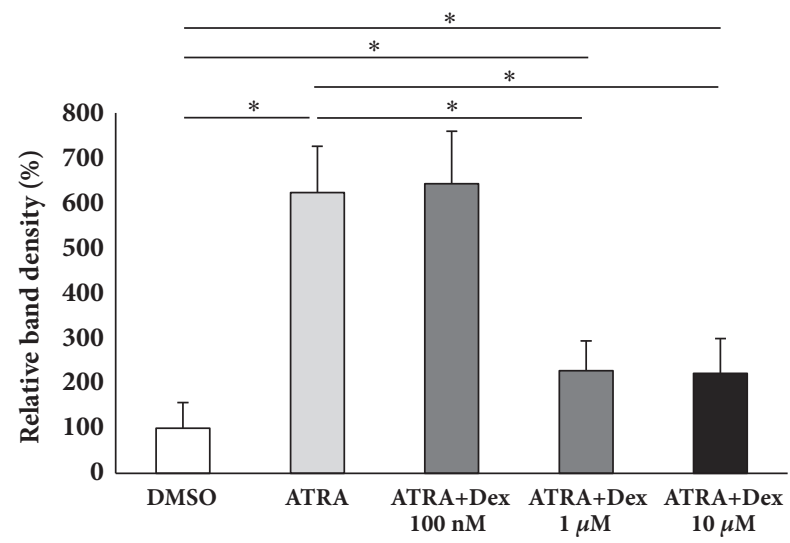

(b)

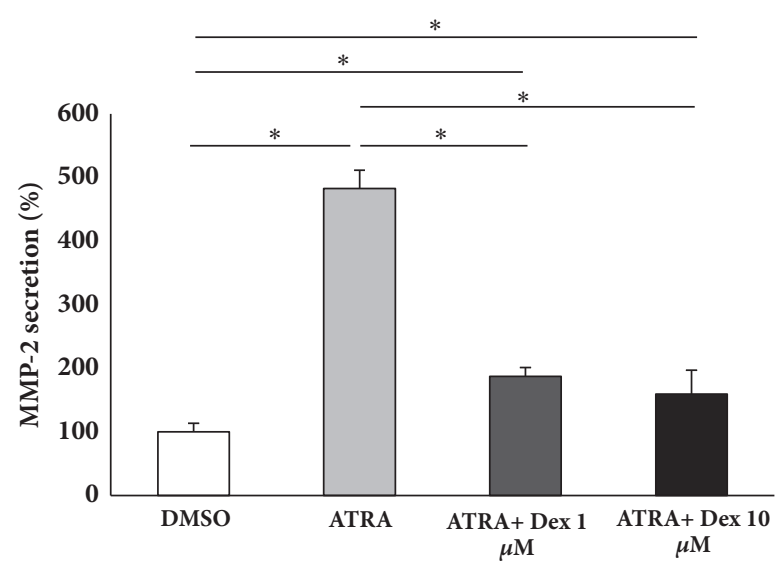

(c)

FIGURE 5: Dexamethasone suppresses ATRA-induced MMP-2 secretion. Cells were pretreated with different concentrations of dexamethasone (Dex) as indicated above for $2 \mathrm{~h}$ and were followed by ATRA treatment for $48 \mathrm{~h}$. The culture supernatants were collected, concentrated by filtration, and subjected to western blot analysis (a). Densitometric analysis of MMP-2 bands shown in (a) was performed by ChemiDoc MP System (b). Cells were pretreated with 1 or $10 \mu \mathrm{M}$ dexamethasone for $2 \mathrm{~h}$ and were followed by ATRA treatment for $48 \mathrm{~h}$. The culture supernatants were used for ELISA (c). * p $<0.05$

that the RAR agonist alone could induce MMP-2 secretion, while the RAR antagonist alone could reverse ATRA-induced MMP-2 secretion, suggesting that ATRA-enhanced MMP2 expression and secretion depend on the RAR signaling pathway. However, since ATRA does not bind to RXR, our finding that the RXR agonist alone is able to induce MMP2 secretion, which can be reversed by the RXR antagonist alone, is also indicative that MMP-2 secretion is independent of the RAR mechanisms. Since the RXR agonist, LG100268, used in this study, was capable of activating the PPAR $\gamma$-RXR heterodimers, PPAR $\alpha$-RXR heterodimers [62], and RXR homodimers [63], the MMP-2 secretion could be mediated by the RXR homodimer signaling pathway or PPAR-dependent mechanisms in addition to the RAR signaling pathway.

In this study, ATRA increased the intracellular calcium levels, and the calcium-channel blocker, verapamil, inhibited ATRA-induced MMP-2 secretion, suggesting that calcium influx is necessary for ATRA-induced MMP-2 secretion. Our results agree with that of the previous study, which showed that ATRA increased the intracellular calcium levels of human teratocarcinoma cells [64]. In that study, the authors demonstrated that the increase in intracellular calcium levels of ATRA-treated cells was due to increased expression of calcium channels. Our results are also in line with earlier findings that calcium ions are required to induce MMP2 expression [65]. In addition, Zhang et al. demonstrated that enhanced levels of intracellular calcium ions and MMP2 expression are associated with metastasis of lung cancer cells [66]. Taken together, our results suggest that ATRA induces calcium influx, which may be due to enhanced calcium-channel expression, and is involved in the induction of MMP-2 secretion in human myeloid leukemia THP-1 cells. However, the precise mechanisms of the ATRA-induced increase in intracellular calcium levels and MMP-2 secretion must be clarified in future studies.

In summary, our results show, for the first time, that ATRA enhances MMP-2 expression and secretion in human myeloid leukemia THP-1 cells in a calcium ion dependent manner through RAR-dependent and independent signaling pathways, and this enhanced secretion was reversed by dexamethasone treatment. We suggest that this enhanced expression and secretion of MMP-2 induced by ATRA treatment may be associated with the possible mechanisms of RAS.

\section{Abbreviations \\ ATRA: All-trans retinoic acid \\ RAR: Retinoic acid receptor \\ RXR: Retinoid X receptor \\ MMP: Matrix metalloproteinase \\ RAS: Retinoic acid syndrome.}

\section{Data Availability}

The data used to support the findings of this study are available from the corresponding author upon request.

\section{Conflicts of Interest}

The authors declare that they have no conflicts of interest. 


\section{Acknowledgments}

This research was supported by Basic Science Research Program through the National Research Foundation of Korea (NRF) funded by the Ministry of Education (NRF2015R1D1A1A01059876).

\section{References}

[1] M. Clagett-Dame and H. F. DeLuca, "The role of vitamin A in mammalian reproduction and embryonic development," Annual Review of Nutrition, vol. 22, pp. 347-381, 2002.

[2] C. B. Stephensen, "Vitamin A, infection, and immune function," Annual Review of Nutrition, vol. 21, pp. 167-192, 2001.

[3] M. E. Huang, Y. C. Ye, S. R. Chen et al., "Use of all-trans-retinoic acid in the treatment of acute promyelocytic leukemia," Blood, vol. 72, pp. 567-572, 1988.

[4] S. Castaigne, C. Chomienne, M. T. Daniel et al., "All-trans retinoic acid as a differentiation therapy for acute promyelocytic leukemia. I. Clinical results," Blood, vol. 76, no. 9, pp. 1704-1709, 1990.

[5] F. Grignani, P. F. Ferrucci, U. Testa et al., "The acute promyelocytic leukemia-specific PML-RAR $\alpha$ fusion protein inhibits differentiation and promotes survival of myeloid precursor cells," Cell, vol. 74, no. 3, pp. 423-431, 1993.

[6] R. P. Warrell Jr., H. de The, Z.-Y. Wang, and L. Degos, "Acute promyelocytic leukemia," The New England Journal of Medicine, vol. 329, no. 3, pp. 177-189, 1993.

[7] P. Fenaux, C. Chomienne, and L. Degos, "Acute promyelocytic leukemia: Biology and treatment," Seminars in Oncology, vol. 24, no. 1, pp. 92-102, 1997.

[8] R. Nasr, V. Lallemand-Breitenbach, J. Zhu, M.-C. Guillemin, and H. De Thé, "Therapy-induced PML/RARA proteolysis and acute promyelocytic leukemia cure," Clinical Cancer Research, vol. 15, no. 20, pp. 6321-6326, 2009.

[9] J. Jing, C. Nelson, J. Paik, Y. Shirasaka, J. K. Amory, and N. Isoherranen, "Physiologically Based Pharmacokinetic Model of All-trans-Retinoic Acid with Application to Cancer Populations and Drug Interactions," The Journal of Pharmacology and Experimental Therapeutics, vol. 361, no. 2, pp. 246-258, 2017.

[10] M. A. M. Ali, A. K. Chow, A. D. Kandasamy et al., "Mechanisms of cytosolic targeting of matrix metalloproteinase-2," Journal of Cellular Physiology, vol. 227, no. 10, pp. 3397-3404, 2012.

[11] H.-J. Ra and W. C. Parks, "Control of matrix metalloproteinase catalytic activity," Matrix Biology, vol. 26, no. 8, pp. 587-596, 2007.

[12] M. Anghelina, A. Schmeisser, P. Krishnan, L. Moldovan, R. H. Strasser, and N. I. Moldovan, "Migration of monocytes/ macrophages in vitro and in vivo is accompanied by MMP12dependent tunnel formation and by neovascularization," Cold Spring Harbor Symposium on Quantitative Biology, vol. 67, pp. 209-215, 2002.

[13] L. Cao, C. Chen, H. Zhu et al., "MMP16 is a marker of poor prognosis in gastric cancer promoting proliferation and invasion," Oncotarget, vol. 7, no. 32, pp. 51865-51874, 2016.

[14] A. Pardo, S. Cabrera, M. Maldonado, and M. Selman, "Role of matrix metalloproteinases in the pathogenesis of idiopathic pulmonary fibrosis," Respiratory Research, vol. 17, no. 1, article no. 23, 2016.

[15] J. E. Koblinski, M. Ahram, and B. F. Sloane, "Unraveling the role of proteases in cancer," Clinica Chimica Acta, vol. 291, no. 2, pp. 113-135, 2000.
[16] K. Nabeshima, T. Inoue, Y. Shimao, and T. Sameshima, "Matrix metalloproteinases in tumor invasion: role for cell migration," Pathology International, vol. 52, no. 4, pp. 255-264, 2002.

[17] K. Kessenbrock, V. Plaks, and Z. Werb, "Matrix metalloproteinases: regulators of the tumor microenvironment," Cell, vol. 141 , no. 1, pp. 52-67, 2010.

[18] E. C. Finger and A. J. Giaccia, "Hypoxia, inflammation, and the tumor microenvironment in metastatic disease," Cancer and Metastasis Reviews, vol. 29, no. 2, pp. 285-293, 2010.

[19] I. Massova, L. P. Kotra, R. Fridman, and S. Mobashery, "Matrix metalloproteinases: structures, evolution, and diversification," The FASEB Journal, vol. 12, no. 12, pp. 1075-1095, 1998.

[20] A. Schröpfer, U. Kammerer, M. Kapp, J. Dietl, S. Feix, and J. Anacker, "Expression pattern of matrix metalloproteinases in human gynecological cancer cell lines," BMC Cancer, vol. 10, no. 1, p. $553,2010$.

[21] M. Okada, N. Murata, and H. Yamawaki, "Canstatin stimulates migration of rat cardiac fibroblasts via secretion of matrix metalloproteinase-2," American Journal of Physiology-Cell Physiology, vol. 312, no. 3, pp. C199-C208, 2017.

[22] M. C. Bi, N. Hose, C. L. Xu et al., "Nonlethal Levels of Zeaxanthin Inhibit Cell Migration, Invasion, and Secretion of MMP-2 via NF- $\kappa$ B Pathway in Cultured Human Uveal Melanoma Cells," Journal of Ophthalmology, vol. 2016, Article ID 8734309, 8 pages, 2016.

[23] A. Papi, G. Bartolini, K. Ammar et al., "Inhibitory effects of retinoic acid and IIF on growth, migration and invasiveness in the U87MG human glioblastoma cell line," Oncology Reports, vol. 18, no. 4, pp. 1015-1021, 2007.

[24] M. W. Roomi, T. Kalinovsky, M. Rath, and A. Niedzwiecki, "Modulation of MMP-2 and MMP-9 secretion by cytokines, inducers and inhibitors in human glioblastoma T-98G cells," Oncology Reports, vol. 37, no. 3, pp. 1907-1913, 2017.

[25] A. Dutta, T. Sen, A. Banerji, S. Das, and A. Chatterjee, "Studies on multifunctional effect of all-trans retinoic acid (ATRA) on matrix metalloproteinase-2 (MMP-2) and its regulatory molecules in human breast cancer cells (MCF-7)," Journal of Oncology, vol. 2009, Article ID 627840, 13 pages, 2009.

[26] M. W. Roomi, J. C. Monterrey, T. Kalinovsky, A. Niedzwiecki, and M. Rath, "Modulation of MMP-2 and MMP-9 by cytokines, mitogens and inhibitors in lung cancer and malignant mesothelioma cell lines," Oncology Reports, vol. 22, no. 6, pp. 1283-1291, 2009.

[27] M. W. Roomi, J. C. Monterrey, T. Kalinovsky, M. Rath, and A. Niedzwiecki, "In vitro modulation of MMP-2 and MMP-9 in human cervical and ovarian cancer cell lines by cytokines, inducers and inhibitors," Oncology Reports, vol. 23, no. 3, pp. 605-614, 2010.

[28] M. W. Roomi, T. Kalinovsky, J. Monterrey, M. Rath, and A. Niedzwiecki, "In vitro modulation of MMP-2 and MMP-9 in adult human sarcoma cell lines by cytokines, inducers and inhibitors," International Journal of Oncology, vol. 43, no. 6, pp. 1787-1798, 2013.

[29] M. W. Roomi, T. Kalinovsky, M. Rath, and A. Niedzwiecki, "In vitro modulation of MMP-2 and MMP-9 in pediatric human sarcoma cell lines by cytokines, inducers and inhibitors," International Journal of Oncology, vol. 44, no. 1, pp. 27-34, 2014.

[30] A.-M. Chambaut-Guérin, S. Hérigault, P. Rouet-Benzineb, C. Rouher, and C. Lafuma, "Induction of matrix metalloproteinase MMP-9 (92-kDa gelatinase) by retinoic acid in human neuroblastoma SKNBE cells: Relevance to neuronal differentiation," Journal of Neurochemistry, vol. 74, no. 2, pp. 508-517, 2000. 
[31] H. J. Lee, M. K. Park, H. Bae, H. Yoon, S. Kim, and C. Lee, "Transglutaminase-2 Is Involved in All-Trans Retinoic AcidInduced Invasion and Matrix Metalloproteinases Expression of SH-SY5Y Neuroblastoma Cells via NF- $\kappa$ B Pathway," Biomolecules \& Therapeutics, vol. 20, no. 3, pp. 286-292, 2012.

[32] A. Safina, M.-Q. Ren, E. Vandette, and A. V. Bakin, "TAK1 is required for TGF- $\beta 1$-mediated regulation of matrix metalloproteinase-9 and metastasis," Oncogene, vol. 27, no. 9, pp. 1198-1207, 2008.

[33] Y. Itoh, A. Ito, K. Iwata, K. Tanzawa, Y. Mori, and H. Nagase, "Plasma membrane-bound tissue inhibitor of metalloproteinases (TIMP)-2 specifically inhibits matrix metalloproteinase 2 (gelatinase A) activated on the cell surface," The Journal of Biological Chemistry, vol. 273, no. 38, pp. 24360-24367, 1998.

[34] P. Chambon, "A decade of molecular biology of retinoic acid receptors," The FASEB Journal, vol. 10, no. 9, pp. 940-954, 1996.

[35] T. Kobayashi, S. Hattori, Y. Nagai, S. Tajima, and T. Nishikawa, "Differential regulation of MMP-2 and MMP-9 gelatinases in cultured human keratinocytes," Dermatology, vol. 197, no. 1, pp. $1-5,1998$.

[36] T. Kobayashi, S. Hattori, Y. Nagai, and S. Tajima, "Differential regulation of the secretions of matrix metalloproteinase9 and tissue inhibitor of metalloproteinases-1 from human keratinocytes in culture," IUBMB Life, vol. 50, no. 3, pp. 221226, 2000.

[37] T. Kobayashi, J. Kishimoto, Y. Ge et al., "A novel mechanism of matrix metalloproteinase- 9 gene expression implies a role for keratinization," EMBO Reports, vol. 2, no. 7, pp. 604-608, 2001.

[38] T. Mayanagi, T. Morita, K. Hayashi, K. Fukumoto, and K. Sobue, "Glucocorticoid receptor-mediated expression of caldesmon regulates cell migration via the reorganization of the actin cytoskeleton," The Journal of Biological Chemistry, vol. 283, no. 45, pp. 31183-31196, 2008.

[39] X.-G. Meng and S.-W. Yue, "Dexamethasone disrupts cytoskeleton organization and migration of T47D human breast cancer cells by modulating the AKT/mTOR/RhoA pathway," Asian Pacific Journal of Cancer Prevention, vol. 15, no. 23, pp. 1024510250, 2014.

[40] E. R. Fietz, C. R. Keenan, G. López-Campos et al., "Glucocorticoid resistance of migration and gene expression in a daughter MDA-MB-231 breast tumour cell line selected for high metastatic potential," Scientific Reports, vol. 7, no. 1, 2017.

[41] M. C. Chen, S. L. Hsu, H. Lin, and T. Yang, "Retinoic acid and cancer treatment," Biomedicine, vol. 4, p. 22, 2014.

[42] F. Alizadeh, A. Bolhassani, A. Khavari, S. Z. Bathaie, T. Naji, and S. A. Bidgoli, "Retinoids and their biological effects against cancer," International Immunopharmacology, vol. 18, no. 1, pp. 43-49, 2014.

[43] E. I. Deryugina and J. P. Quigley, "Matrix metalloproteinases and tumor metastasis," Cancer and Metastasis Reviews, vol. 25, no. 1, pp. 9-34, 2006.

[44] H. Nagase and J. F. Woessner Jr., "Matrix metalloproteinases," The Journal of Biological Chemistry, vol. 274, no. 31, pp. 2149121494, 1999.

[45] W. Hornebeck, H. Emonard, J.-C. Monboisse, and G. Bellon, "Matrix-directed regulation of pericellular proteolysis and tumor progression," Seminars in Cancer Biology, vol. 12, no. 3, pp. 231-241, 2002.

[46] M. Seiki, "Membrane-type 1 matrix metalloproteinase: a key enzyme for tumor invasion," Cancer Letters, vol. 194, no. 1, pp. 1-11, 2003.
[47] S. L. Parsons, S. A. Watson, H. M. Collins, N. R. Griffin, P. A. Clarke, and R. J. C. Steele, "Gelatinase (MMP-2 and -9) expression in gastrointestinal malignancy," British Journal of Cancer, vol. 78, no. 11, pp. 1495-1502, 1998.

[48] N. Cox and H. O'Brien, "Sweet's syndrome associated with trans-retinoic acid treatment in acute promyelocytic leukemia," Clinical and Experimental Dermatology, vol. 19, no. 1, pp. 51-52, 1994.

[49] S. R. Frankel, A. Eardley, G. Lauwers, M. Weiss, and R. P. Warrell Jr., "The 'retinoic acid syndrome' in acute promyelocytic leukemia," Annals of Internal Medicine, vol. 117, no. 4, pp. 292296, 1992.

[50] G. Taraboletti, P. Borsotti, R. G. S. Chirivi et al., "Effect of all trans-retinoic acid (ATRA) on the adhesive and motility properties of acute promyelocytic leukemia cells," International Journal of Cancer, vol. 70, no. 1, pp. 72-77, 1997.

[51] D. C. Brown, H. Tsuji, and R. S. Larson, "All-trans retinoic acid regulates adhesion mechanism and transmigration of the acute promyelocytic leukaemia cell line NB-4 under physiologic flow," British Journal of Haematology, vol. 107, no. 1, pp. 86-98, 1999.

[52] C. Zang, L. Hongyu, C. Ries, M. G. Ismair, and P. E. Petrides, "Enhanced migration of the acute promyelocytic leukemia cell line NB4 under in vitro conditions during short-term all-transretinoic acid treatment," Journal of Cancer Research and Clinical Oncology, vol. 126, no. 1, pp. 33-40, 2000.

[53] L. Vahdat, P. Maslak, W. H. Miller Jr. et al., "Early mortality and the retinoic acid syndrome in acute promyelocytic leukemia: Impact of leukocytosis, low-dose chemotherapy, PMN/RAR- $\alpha$ isoform, and CD13 expression in patients treated with all-trans retinoic acid," Blood, vol. 84, no. 11, pp. 3843-3849, 1994.

[54] R. P. Warrell Jr., P. Maslak, A. Eardley, G. Heller, W. H. Miller Jr., and S. R. Frankel, "Treatment of acute promyelocytic leukemia with all-trans retinoic acid: An update of the New York experience," Leukemia, vol. 8, no. 6, pp. 929-933, 1994.

[55] M. R. Nicolls, L. S. Terada, R. M. Tuder, S. A. Prindiville, and M. I. Schwarz, "Diffuse alveolar hemorrhage with underlying pulmonary capillaritis in the retinoic acid syndrome," American Journal of Respiratory and Critical Care Medicine, vol. 158, no. 4, pp. 1302-1305, 1998.

[56] A. E. Coutinho and K. E. Chapman, "The anti-inflammatory and immunosuppressive effects of glucocorticoids, recent developments and mechanistic insights," Molecular and Cellular Endocrinology, vol. 335, no. 1, pp. 2-13, 2011.

[57] A. R. Farina, M.-P. Masciulli, A. Tacconelli et al., "All-transretinoic acid induces nuclear factor $\kappa \mathrm{B}$ activation and matrix metalloproteinase- 9 expression and enhances basement membrane invasivity of differentiation-resistant human SK-N-BE 9N neuroblastoma cells," Cell Growth \& Differentiation, vol. 13, no. 8, pp. 343-354, 2002.

[58] Y.-Q. Lan, C. Zhang, J.-H. Xiao et al., "Suppression of I $\kappa \mathrm{B} \alpha$ increases the expression of matrix metalloproteinase- 2 in human ciliary muscle cells," Molecular Vision, vol. 15, pp. 19771987, 2009.

[59] M. M. Aagaard, R. Siersbæk, and S. Mandrup, "Molecular basis for gene-specific transactivation by nuclear receptors," Biochimica et Biophysica Acta, vol. 1812, no. 8, pp. 824-835, 2011.

[60] M. Tsai and B. W. O’Malley, "Molecular mechanisms of action of steroid/thyroid receptor superfamily members," Annual Review of Biochemistry, vol. 63, pp. 451-486, 1994.

[61] P. Chambon, A. Zelent, M. Petkovich et al., "The family of retinoic acid nuclear receptors," in Retinoids: 10 Years On, L.-H. Sanrat, Ed., pp. 10-27, Karger/Basel, 1991. 
[62] R. Mukherjee, J. Strasser, L. Jow, P. Hoener, J. R. Paterniti, and R. A. Heyman, "RXR Agonists Activate PPAR $\alpha$-Inducible Genes, Lower Triglycerides, and Raise HDL Levels In Vivo," Arteriosclerosis, Thrombosis, and Vascular Biology, vol. 18, no. 2, pp. 272-276, 1998.

[63] D. J. Mangelsdorf and R. M. Evans, "The RXR heterodimers and orphan receptors," Cell, vol. 83, no. 6, pp. 841-850, 1995.

[64] Z.-Y. Gao, G. Xu, M. M. Stwora-Wojczyk, F. M. Matschinsky, V. M.-Y. Lee, and B. A. Wolf, "Retinoic acid induction of calcium channel expression in human NT2N neurons," Biochemical and Biophysical Research Communications, vol. 247, no. 2, pp. 407413, 1998.

[65] E. C. Kohn, W. Jacobs, Y. S. Kim et al., "Calcium influx modulates expression of matrix metalloproteinase-2 (72-kDa type IV collagenase, gelatinase A)," Journal of Biological Chemistry, vol. 269, pp. 21505-21511, 1994.

[66] J. Zhang, G. Liu, Y. Meng, H. Lin, and Y. Lu, "MAG-2 promotes invasion, mobility and adherence capability of lung cancer cells by MMP-2, CD44 and intracellular calcium in vitro," Oncology Reports, vol. 21, no. 3, pp. 697-706, 2009. 


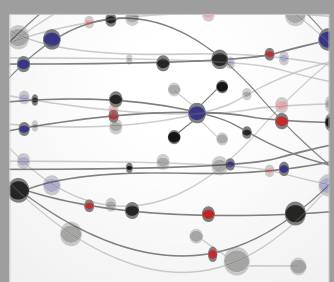

The Scientific World Journal
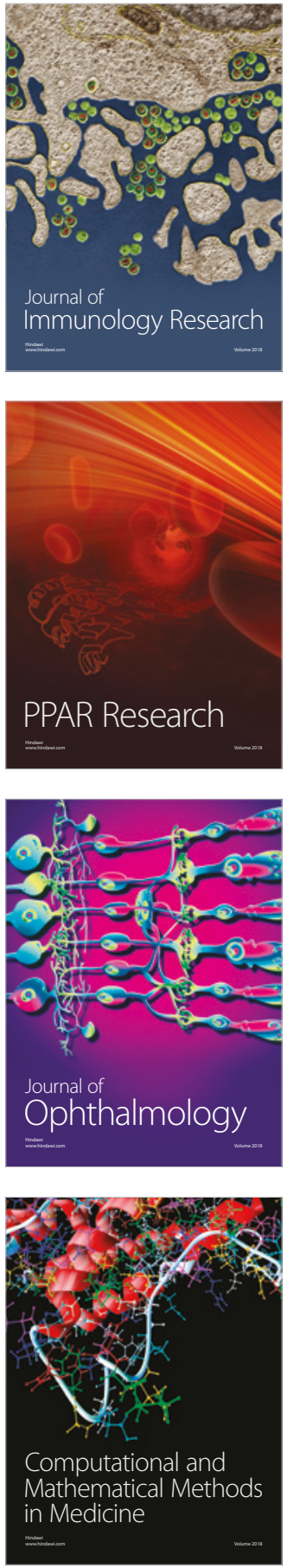

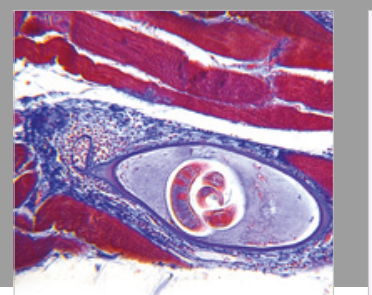

Gastroenterology Research and Practice

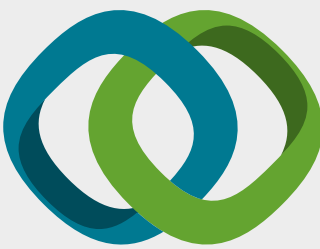

\section{Hindawi}

Submit your manuscripts at

www.hindawi.com
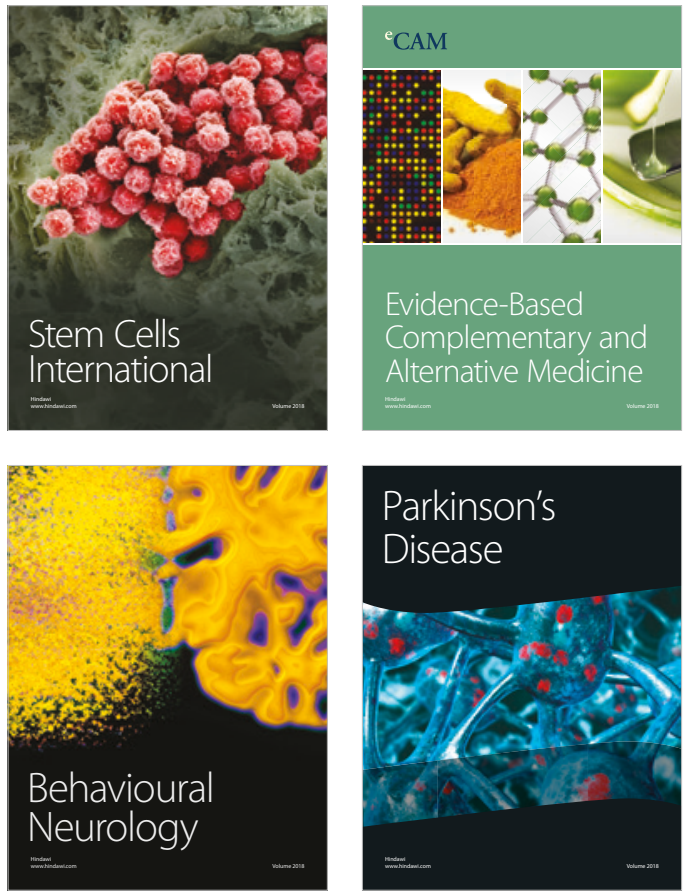

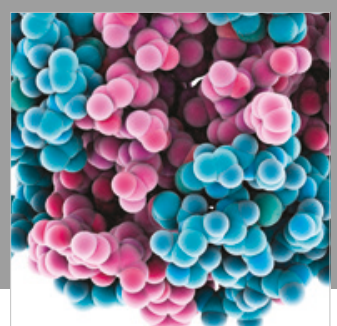

ournal of

Diabetes Research

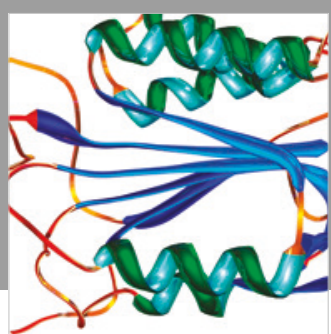

Disease Markers
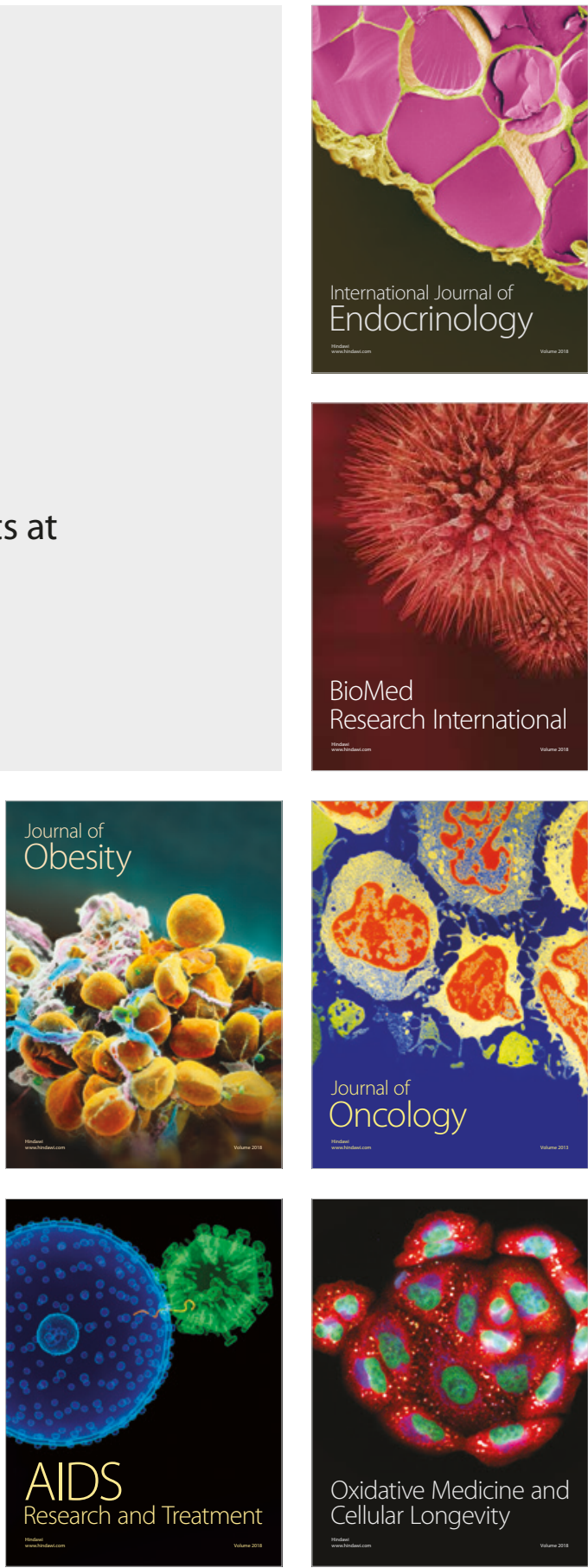